\title{
The Effect of Solifenacin on Cognitive Function following Stroke
}

Jin-Woo Park

Department of Physical Medicine and Rehabilitation, Dongguk University Ilsan Hospital, Goyang-si, Republic of Korea

\section{Key Words}

Stroke $\cdot$ Cognitive symptoms · Anticholinergics · Solifenacin $\cdot$ Muscarinic receptors

\begin{abstract}
Background/Aims: Our aim was to investigate the effect of solifenacin (an anticholinergic) on cognitive function after stroke. Methods: We retrospectively reviewed 66 stroke cases who were prescribed solifenacin for more than 2 months. A control group was generated matching the patients both for sex and age. The interval changes in the Mini-Mental State Examination (MMSE) score and Clinical Dementia Rating Sum of Boxes (CDR-SB) score after solifenacin administration were compared to those of the control group. Results: The baseline MMSE score of the control group was $15.9 \pm 9.2$ and that of the solifenacin group was $14.3 \pm 7.8$. After using solifenacin for an average of 76.9 days, there was a change in the MMSE score of $1.9 \pm 5.2$. During similar periods, there was a change in the MMSE score of $2.9 \pm 3.7$ in the control group (not using solifenacin). However, there was no significant difference between the two groups. Similarly, there was no significant difference in the CDR-SB score between the two groups. Conclusion: Solifenacin treatment did not affect the short-term cognitive performance in stroke patients. This information might be useful when prescribing anticholinergics to stroke patients.

Copyright (c) 2013 S. Karger AG, Basel
\end{abstract}

\section{Introduction}

Neurogenic bladder after stroke, especially bladder storage problems, is frequent [1], and the disruption of the neuromicturition pathways might result in bladder hyperreflexia and urgency incontinence [2]. Anticholinergics have been used to improve detrusor overactivity and increase bladder capacity after stroke [3]. 
The central nervous system of older patients is very sensitive to adverse anticholinergic effects due to the significant decrease in cholinergic neurons or receptors in their brains, the reduction in the hepatic metabolism and renal excretion of medications as well as the increase in the blood-brain barrier permeability [4]. Many studies have found an association between the anticholinergic activity of medications and cognitive impairment or dementia $[5,6]$. On the other hand, stroke is independently related to cognitive dysfunction. The prevalence of dementia in individuals with a history of stroke is about $30 \%$, and the incidence of dementia is increased after stroke [7].

Do anticholinergics really worsen cognitive dysfunction after stroke? Currently, there is little known about this subject, but the answer may depend on the selectivity for muscarinic receptors or the permeability of the blood-brain barrier. In this study, we investigated whether solifenacin (an anticholinergic which has a high affinity for the muscarinic M3 receptor) has a negative effect on cognitive function after stroke.

\section{Methods}

\section{Subjects}

This was a retrospective case-control study. Medical charts were retrospectively reviewed for all individuals with a diagnosis of stroke who were admitted for rehabilitation to the university hospital from January 2010 to December 2011. A total of 72 consecutive patients were thus identified who were on a 2 -month treatment course with solifenacin $(5$ or $10 \mathrm{mg}$ ) to control for abnormal urinary frequency or urgency symptoms. Six patients were excluded because data for evaluating their cognitive function [using the Mini-Mental State Examination (MMSE) or Clinical Dementia Rating Sum of Boxes (CDR-SB)] were not available, and therefore, 66 patients were included in this study. 66 age- and sex-matched stroke patients, who had not been prescribed anticholinergics during the same periods, were also selected as a control group for the comparison of changes in cognitive function. This study was approved by our Institutional Review Board.

\section{Outcome Measures}

In our rehabilitation setting, cognitive function tests are routinely performed by a trained physician during a patient's admission period; therefore, these data could be collected via a chart review of all patients selected for the study (from January 2010 to December 2011). Cognitive function was determined using the MMSE [8] and the CDR-SB [9].

The MMSE provides a quick evaluation of cognitive function and is often used to screen for dementia or monitor its progression. The MMSE tests orientation, registration, attention and calculation, recall, praxis and language, and is scored on a 30-point scale (30 being normal and 1 being severely impaired).

The CDR was initially developed as a staging instrument to test for Alzheimer's disease severity [10] and covers the following 6 categories or 'boxes': memory, orientation, judgment and problem solving, community affairs, home and hobbies, and personal care. The CDR global ratings are calculated using a complex algorithm and range from 0 (no dementia) to 3 (severe dementia) [11]. The CDR-SB scores are calculated by simply adding the box scores; therefore, they range from 0 to 18 (higher scores indicate more impairment). The CDR-SB has been proposed as a sole primary end point for disease-modifying trials on Alzheimer's disease [9].

\section{Statistical Analysis}

Statistical analyses were performed using SPSS version 12.0 (SPSS, Inc., Chicago, Ill., USA). Quantitative variables are expressed as means \pm SD, and qualitative variables are 
Table 1. General characteristics of the study participants

\begin{tabular}{|c|c|c|c|}
\hline & $\begin{array}{l}\text { Solifenacin group } \\
(n=66)\end{array}$ & $\begin{array}{l}\text { Control group } \\
(n=66)\end{array}$ & $\mathrm{p}$ value \\
\hline Mean age $\pm S D$, years & $69.3 \pm 11.5$ & $69.3 \pm 11.5$ & NS \\
\hline Minimum-maximum & $49-86$ & $49-86$ & \\
\hline Gender & & & NS \\
\hline Male & 18 & 18 & \\
\hline Female & 48 & 48 & \\
\hline \multicolumn{4}{|l|}{ Etiology } \\
\hline \multicolumn{4}{|l|}{ Intracerebral hemorrhage } \\
\hline Basal ganglia & 26 & 24 & \\
\hline Thalamic & 9 & 10 & \\
\hline Cerebellar & 3 & 2 & \\
\hline Pontine & 1 & 3 & \\
\hline \multicolumn{4}{|l|}{ Infarction } \\
\hline Middle cerebral artery & 18 & 18 & \\
\hline Striatocapsular & 7 & 6 & \\
\hline Anterior cerebral artery & 0 & 2 & \\
\hline Thalamic & 2 & 1 & \\
\hline Mean duration of illness (stroke) $\pm \mathrm{SD}$, days & $58.5 \pm 40.6$ & $56.0 \pm 21.2$ & NS \\
\hline Minimum-maximum & $26-100$ & $16-115$ & \\
\hline Mean MMSE score \pm SD (at baseline) & $14.3 \pm 7.8$ & $15.9 \pm 9.2$ & NS \\
\hline Minimum-maximum & $0-26$ & $0-26$ & \\
\hline Mean CDR-SB score \pm SD (at baseline) & $10.1 \pm 4.8$ & $8.1 \pm 6.2$ & NS \\
\hline Minimum-maximum & $1.5-18$ & $0-18$ & \\
\hline Mean duration of solifenacin use $\pm \mathrm{SD}$, days & $76.9 \pm 12.5$ & & \\
\hline Minimum-maximum & $60-108$ & & \\
\hline Mean interval between baseline and follow-up \pm SD, days & $91.5 \pm 18.3$ & $90.4 \pm 19.3$ & NS \\
\hline Minimum-maximum & $64-132$ & $62-130$ & \\
\hline
\end{tabular}

NS $=$ Not significant

expressed as absolute values. Group comparisons of baseline demographics and clinical characteristics (sex, age, duration of illness, MMSE, CDR-SB) were performed using Student's test for continuous variables and the $\chi^{2}$ test for categorical variables to test for unbalancing between the groups. Changes in the MMSE and CDR-SB scores after more than 2 months of solifenacin treatment were compared between the two groups using Student's test. The significance level was set at $\mathrm{p}<0.05$.

\section{Results}

The average age in both groups was $69.3 \pm 11.5$ years. There were 18 males and 48 females in each group. The general characteristics of the participants are shown in table 1. There were no significant differences between the groups with respect to demographic variables, duration of illness, baseline MMSE score, baseline CDR-SB score and interval between baseline and follow-up test. The average duration of solifenacin use was $76.9 \pm 12.5$ days.

There were changes in the MMSE score of $1.95 \pm 5.22$ in the solifenacin group and of 2.91 \pm 3.65 in the control group. Neither was significantly different between the two groups. There were changes in the CDR-SB score of $-1.16 \pm 2.65$ in the solifenacin group and of $-1.00 \pm 2.27$ in the control group. Neither was significantly different between the two groups (fig. 1). 


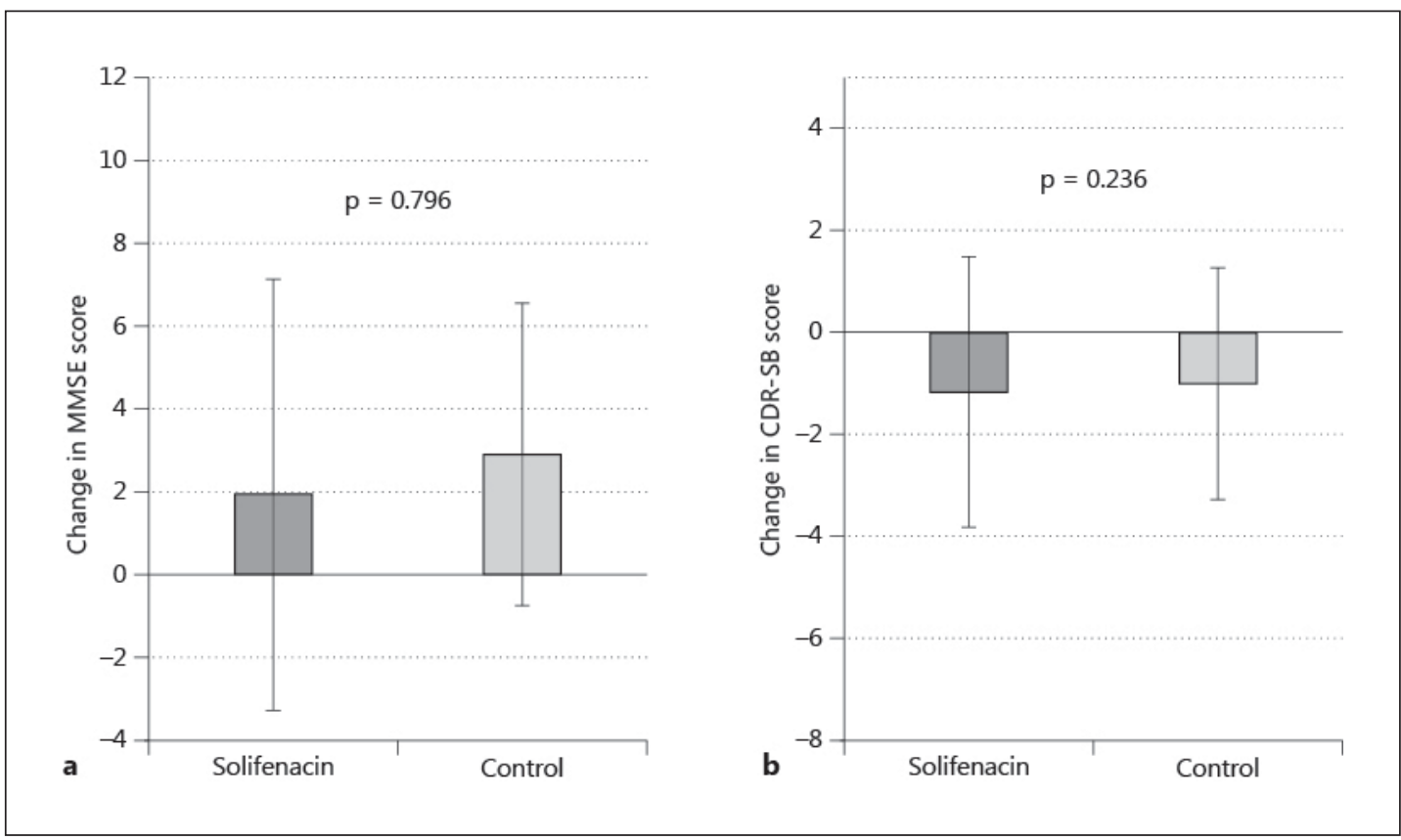

Fig. 1. Comparison between the solifenacin and control groups with respect to changes in the cognitive function tests. a MMSE. $\mathbf{b}$ CDR-SB. Boxes = Average scores; whiskers = standard deviations.

\section{Discussion}

This study showed that the use of solifenacin for 2 months does not affect the cognitive performance after stroke. There are two possible factors that may be responsible for this result: one is the muscarinic receptor selectivity and the other is the blood-brain barrier permeability.

Acetylcholine is the best-known neurotransmitter involved in micturition and is released from parasympathetic nerve endings. Five muscarinic receptor subtypes (M1-M5) have been identified by both molecular biological and pharmacological investigations [12], of which the muscarinic M2 and M3 receptor subtypes are located postsynaptically on the detrusor smooth muscle. Although the muscarinic M3 receptor is a minority in this tissue, it has been shown to play a predominant role in mediating detrusor smooth muscle contraction $[13,14]$. The muscarinic M1 receptor subtype is considered to be involved in learning and memory processes in the central nervous system, and side effects in the central nervous system due to antimuscarinic agents are related to this M1 receptor [15]. Even though the blood-brain barrier permeability is increased after stroke [16], solifenacin has a higher affinity for the muscarinic M3 receptor than the M1 receptor $[17,18]$; therefore, solifenacin might not increase cognitive dysfunction after stroke.

Cognitive dysfunction is a common sequela of stroke. The acute phase of cognitive impairment after stroke is related to its direct local effects as well as hypoperfusion [19] and functional deactivation (diaschisis) in nearby or remote areas of the brain [20]. The prognosis regarding the development of cognitive disorders after stroke is generally favorable and recovery is possible [21]. In this study, cognitive dysfunction was found in both groups, but the average MMSE and CDR-SB scores were improved at follow-up regardless of whether solifenacin was used or not. 
Park: The Effect of Solifenacin on Cognitive Function following Stroke

This study was based on retrospective chart reviews, and the study group consisted of only a small number of patients. To compensate for these limitations, we used an age- and sex-matched control group; however, this still is not as effective as a prospective randomized control study. Another limitation may be the 2-month period of solifenacin treatment, which can be considered somewhat short.

Solifenacin treatment did not worsen the short-term cognitive performance in stroke patients. This information might be useful when prescribing anticholinergics to stroke patients. However, there should further be a large-size study in the future.

\section{Disclosure Statement}

There are no conflicts of interest.

\section{References}

1 Ersoz M, Tunc H, Akyuz M, Ozel S: Bladder storage and emptying disorder frequencies in hemorrhagic and ischemic stroke patients with bladder dysfunction. Cerebrovasc Dis 2005;20:395-399.

-2 Gelber DA, Good DC, Laven LJ, Verhulst SJ: Causes of urinary incontinence after acute hemispheric stroke. Stroke 1993;24:378-382.

3 Suzuki M, Ohtake A, Yoshino T, Yuyama H, Hayashi A, Ukai M, Okutsu H, Noguchi Y, Sato S, Sasamata M: Effects of solifenacin succinate (YM905) on detrusor overactivity in conscious cerebral infarcted rats. Eur J Pharmacol 2005;512:61-66.

4 Tune LE: Anticholinergic effects of medication in elderly patients. J Clin Psychiatry 2001;62(suppl 21):11-14 Campbell N, Boustani M, Limbil T, Ott C, Fox C, Maidment I, Schubert CC, Munger S, Fick D, Miller D, Gulati R: The cognitive impact of anticholinergics: a clinical review. Clin Interv Aging 2009;4:225-233.

6 Campbell NL, Boustani MA, Lane KA, Gao S, Hendrie H, Khan BA, Murrell JR, Unverzagt FW, Hake A, SmithGamble V, Hall K: Use of anticholinergics and the risk of cognitive impairment in an African American population. Neurology 2010;75:152-159.

7 Leys D, Henon H, Mackowiak-Cordoliani MA, Pasquier F: Poststroke dementia. Lancet Neurol 2005;4:752759.

-8 Folstein MF, Folstein SE, McHugh PR: 'Mini-mental state'. A practical method for grading the cognitive state of patients for the clinician. J Psychiatr Res 1975;12:189-198.

$\checkmark 9$ Coley N, Andrieu S, Jaros M, Weiner M, Cedarbaum J, Vellas B: Suitability of the Clinical Dementia Rating-Sum of Boxes as a single primary endpoint for Alzheimer's disease trials. Alzheimers Dement 2011;7:602-610.e2.

10 Hughes CP, Berg L, Danziger WL, Coben LA, Martin RL: A new clinical scale for the staging of dementia. Br J Psychiatry 1982;140:566-572.

11 Morris JC: The Clinical Dementia Rating (CDR): current version and scoring rules. Neurology 1993;43:24122414.

-12 Caulfield MP, Birdsall NJ: International Union of Pharmacology. XVII. Classification of muscarinic acetylcholine receptors. Pharmacol Rev 1998;50:279-290.

13 Eglen RM, Hegde SS, Watson N: Muscarinic receptor subtypes and smooth muscle function. Pharmacol Rev 1996;48:531-565.

14 Eglen RM, Reddy H, Watson N, Challiss RA: Muscarinic acetylcholine receptor subtypes in smooth muscle. Trends Pharmacol Sci 1994;15:114-119.

15 Matsui M, Yamada S, Oki T, Manabe T, Taketo MM, Ehlert FJ: Functional analysis of muscarinic acetylcholine receptors using knockout mice. Life Sci 2004;75:2971-2981.

16 Hatashita S, Hoff JT: Brain edema and cerebrovascular permeability during cerebral ischemia in rats. Stroke 1990;21:582-588.

17 Ikeda K, Kobayashi S, Suzuki M, Miyata K, Takeuchi M, Yamada T, Honda K: M(3) receptor antagonism by the novel antimuscarinic agent solifenacin in the urinary bladder and salivary gland. Naunyn Schmiedebergs Arch Pharmacol 2002;366:97-103.

-18 Ohtake A, Saitoh C, Yuyama H, Ukai M, Okutsu H, Noguchi Y, Hatanaka T, Suzuki M, Sato S, Sasamata M, Miyata K: Pharmacological characterization of a new antimuscarinic agent, solifenacin succinate, in comparison with other antimuscarinic agents. Biol Pharm Bull 2007;30:54-58.

19 Hillis AE, Barker PB, Wityk RJ, Aldrich EM, Restrepo L, Breese EL, Work M: Variability in subcortical aphasia is due to variable sites of cortical hypoperfusion. Brain Lang 2004;89:524-530.

20 Ferro JM: Hyperacute cognitive stroke syndromes. J Neurol 2001;248:841-849.

-21 Rasquin SM, Lodder J, Ponds RW, Winkens I, Jolles J, Verhey FR: Cognitive functioning after stroke: a one-year follow-up study. Dement Geriatr Cogn Disord 2004;18:138-144. 